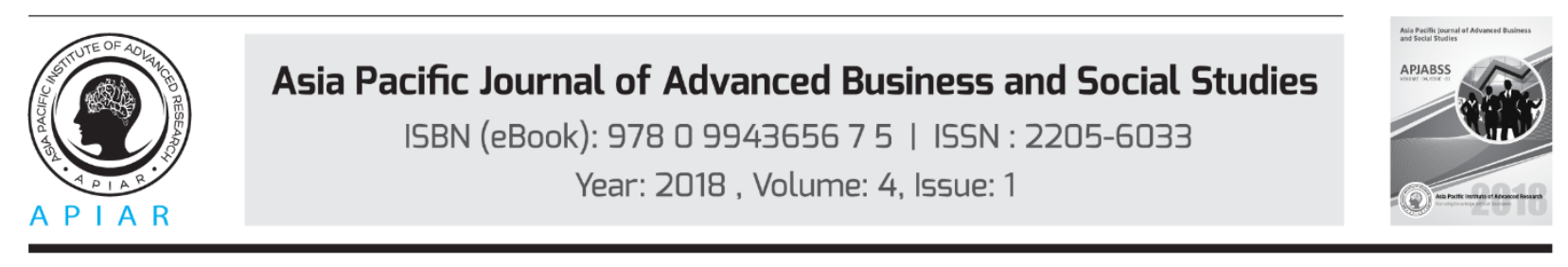

\title{
THE CONTINUED INFLUENCE OF RETRACTED WITNESSTESTIMONY AT JURY TRIALS
}

\author{
Stephanie C. Black \\ Edith Cowan University, Perth, Australia \\ Email: scblack@our.ecu.edu.au
}

\begin{abstract}
The number of legal systems in the Asia Pacific that conduct jury trials is growing. Although, there is evidence corroborating the suitability of jury trials for achieving justice, research also highlights problematic aspects. Eye witness testimony at jury trials, in particular, raises a number of potential issues which include the continuing influence of retracted witness testimony, potentially unsuitable interview techniques, insufficient differentiation between recall and recognition and potential juror prejudice. The problem of withdrawn testimony is considered in relation to the well-researched concept of the continued influence effect. Options for minimisation of the continued influence effect based on the event model concept are explored, for instance, by offering a coherent alternative explanation instead of a simple withdrawal of the testimony. Further discussion explores how concomitant factors affect the severity of the continuing influence of retracted testimony. One such factor is the potential for juror prejudice due to ethnic differences between the accused, witnesses, and jurors. The subject of juror prejudice is examined in the context of the intergroup contact hypothesis and research on indirect and vicarious intergroup contact. Moreover, options to improve the quality of testimonies and to avoid retractions in the first place are discussed. Several research-based recommendations are provided and possible actions are suggested for ameliorating the problems discussed.
\end{abstract}

Keywords: Continued Influence, Jury Trials, Memory, Retraction, Testimony.

\section{Introduction}

Legal justice is a fundamental moral ideal (Cantrall, 1959; Clear \& Karp, 1999; Farrelly, 2007; Oberdiek, 2014), but its implementation in modern society is subject to practical constraints (Bortner, 1982; Carvan, 2015; Farrelly, 2007). The number of legal systems in the Asia Pacific that conduct jury trials is growing (Hans, 2008; McNulty, 2007). Although, there is evidence corroborating the suitability of jury trials for achieving justice (Hans \&Vidmar, 1991; Kairys, Schulman, Harring, \& Beeler, 1975; Schrag \& Scotchmer, 1994), some elements of jury trials are strongly contested, in particular, eyewitness testimony (Chrobak\& Zaragoza, 2008, 2013; Guadagno \& Powell, 2009; Oeberst\& Blank, 2012; Steffens \& Mecklenbräuker, 2007). Eye witness testimony at jury trials raises a number of potential issues, which include the retraction of witness testimony, potentially unsuitable interview techniques, insufficient differentiation between recall and recognition, and potential juror prejudice. Witness testimony retraction raises the possibility of the continuing influence of withdrawn witness testimony, which might have far-reaching implications for individual lives and justice in general. The following 
deliberations will explore this topic further and show how the presence or absence of concomitant factors affects the continued influence of retracted testimony.

\section{The Continued Influence Effect}

When a false statement is subsequently invalidated or withdrawn, recipients often continue to rely on the false information for their decision making; this is termed the continued influence effect (Johnson \& Seifert, 1994). This effect refers to the fact that a withdrawal can be unsuccessful because the false statement can persist in influencing the recipient, even if the recipient remembers the withdrawal of the information (Ecker, Lewandowsky \& Apai, 2010). This continued influence effect is particularly salient for jury trials, for instance, when jurors fail to disregard withdrawn testimony (Fraser \& Stevenson, 2014) or fail to disregard withdrawn conclusions from refuted scientific studies (Greitemeyer, 2014). The continued influence effect can also operate long after a trial, when, despite a full exoneration, acquitted individuals find their reputation indelibly blemished (Greitemeyer \& Sagioglou, 2015). The continued influence effect is a threat not just to objective outcomes of a jury trial, but also to rational decision making in all aspects of modern life that involve information that is prone to change (Ecker et al., 2010). Therefore, much research has been undertaken in an attempt to eradicate the effect, but, unfortunately, much of this research has been unsuccessful (Ecker, Lewandowsky, Swire, \& Chang, 2011; Oeberst \& Blank, 2012).

\subsection{Decreasing the Continued Influence Effect by Providing a Coherent Explanation}

One rare example of a successful study into diminishing the continuing influence effect is that by Ecker et al. (2010), who achieved an amelioration of the effect by providing a causally coherent alternative explanation, and demonstrated that a coherent alternative reduces the continued influence effect better than the simple withdrawal of the false information. This effect is explained with the event model concept (Ecker et al., 2011), which builds on the situation model concept (Zwaan \& Radvansky, 1998). The authors posit that an event is stored in memory as a complete sequence of logically interlocking components. A retraction would cause the removal of a component, thus destroying the completeness of the model. Unfortunately, people prefer complete accounts of events-even if wrong-over correct accounts that are incomplete; therefore, filling the gap that was created by the retraction with a coherent explanation once again completes the event model and allows the new information to be more easily assimilated into memory (Ecker et al., 2010; Ecker et al., 2011; Johnson \& Seifert, 1994).

The above event model concept described by Ecker et al. (2010) aligns well with research on eyewitnesses where it was shown that the preference for causal explanations was so strong that, if they were pressured for a response, witnesses resorted to fabricating coherent explanations where none existed (Chrobak \& Zaragoza, 2008, 2013). According to Chrobak and Zaragoza (2008, 2013), fabrication will decrease if witnesses are asked open questions, and the interviewer refrains from pressing for answers. This aligns with findings by Powell and colleagues that the use of open, rather than closed, questions is supportive for truthful recall (Crossman, Powell, Principe, \& Ceci, 2002; Guadagno \& Powell, 2009; Powell \& Snow, 2007). Broadbent (2013) and Kahneman (1973), similarly, point out that asking fewer open questions is preferable to an excessive number of closed questions.

In conclusion, retractions of witness testimony are less likely to exert a continuing influence upon jurors if the retractions are accompanied by a coherent alternative explanation that sufficiently fills the event model gap remaining after a retraction. Moreover, in order to minimise the temptation to fabricate details to fill existing event model gaps in the recall of an 
event, witnesses should not be repeatedly pressed for answers, and open questions are preferable over closed questions. Unfortunately, research shows that interviewers frequently do not apply suitable interview techniques, even after they have been trained in their use (Darvish, Hershkowitz, Lamb, \&Orbach, 2008; Lamb, Hershkowitz, Orbach, \& Esplin, 2008). Therefore, more research into potential interventions to increase the uptake of good interviewing technique is required.

\subsection{Decreasing the Continued Influence Effect by Decreasing Juror Prejudice}

A second possible approach to diminishing the severity of the continued influence of retracted witness testimony is related to prejudice. According to a study by Ecker, Lewandowsky, Fenton, and Martin (2014), the success of withdrawing false information may be contingent on preexisting attitudes of the recipient. For example, jurors with a particular prejudice toward the defendant might be especially susceptible to continuing to rely on testimony that was subsequently withdrawn if the original false testimony aligns with their specific prejudice. These prejudiced jurors would be more prone to the continued influence effect, compared to participants with a neutral attitude. Conversely, unprejudiced jurors are less apt to base their decisions on withdrawn testimony. Therefore, efforts to avoid juror prejudice take on additional importance. Moreover, assembling an unprejudiced jury has long been a legal ideal, and much effort has been directed to improving jury impartiality (Hans \&Vidmar, 1991; Kairys et al., 1975; Schrag \& Scotchmer, 1994).

Prejudice is a broad social phenomenon that is not just confined to the courtroom. It is characterised by hostility due to generalisations based on group memberships (Allport, 1954; Gaertner\& Dovidio, 2012). Prejudice can have many manifestations, including racial, ethnic, and religious expressions (Haslam \& Holland, 2012). The intergroup contact hypothesis (Allport, 1954) has inspired extensive research (Capozza, Trifiletti, Vezzali, \&Favara, 2013; Gaertner\& Dovidio, 2012; Gaertner, Dovidio, \& Bachman, 1996; Hewstone, Rubin, \& Willis, 2002), which largely found that intergroup contact decreases prejudice. This was subsequently corroborated by a meta-study that analysed several hundred studies (Pettigrew \& Tropp, 2006). Research into intergroup contact was subsequently widened to include indirect intergroup contact, and it was shown that the beneficial effect extends to intergroup contact via audio, visual, and online media (Mazziotta, Mummendey, \& Wright, 2011; Schiappa, Gregg, \& Hewes, 2005; Turner, Crisp, \& Lambert, 2007). However, intergroup contact needs to be perceived as significant, useful, and relevant to the individual (Mazziotta et al., 2011), otherwise it can increase prejudice via the backlash effect (Barlow et al., 2012) based on reactance (Brehm, 1966; Wortman, Brehm, \& Berkowitz, 1975). This body of research carries valuable implications for the design of media content and public interventions for decreasing prejudice, but it is more applicable to long-term interventions aimed at large populations. A more immediate option for decreasing prejudice is offered by Greenhalgh and Watt (2015), who showed that better educated individuals and women display more empathy towards individuals outside their group affiliations. Therefore, selecting more women and highly educated individuals as jurors might aid in decreasing jury prejudice. However, further research is required to weigh the positive effect of this option against the danger of creating a biased jury.

In summary, an unprejudiced jury is less susceptible to the continued influence effect of withdrawn testimony (Ecker et al., 2014). Therefore, it is suggested to select more empathic jurors, such as women and well-educated individuals, which will decrease jury prejudice and, thereby, mitigate the continuing influence of withdrawn testimony. In the long term, the ideal would be to decrease prejudice not just amongst jurors, but population-wide. This goal could be 
advanced, for instance, by designing media content to serve as a form of indirect intergroup contact.

\subsection{Eliminating the Continued Influence Effect by Avoiding Testimony Retractions}

The previous sections have focused on minimising the severity of the continued influence effect in situations where witness testimony has been retracted. However, discussion is not complete without exploring how retractions of witness testimony might be avoided in the first place. The literature contains extensive research on how to avoid false testimony and improve the quality of eyewitness testimony. A significant portion of this research focuses on how different pre-trial procedures such as interviews and line-ups can introduce memory distortion (Roediger \& McDermott, 2000; Zaragoza, Payment, Ackil, Drivdahl, \& Beck, 2001).

As mentioned in the section about mitigating the continued influence effect by offering a coherent alternative explanation, when witnesses are pressured for a response, they might resort to fabricating coherent explanations where none exist (Chrobak \& Zaragoza, 2008, 2013). This fabrication will decrease if witnesses are asked open questions (Broadbent, 2013; Chrobak \& Zaragoza, 2008, 2013; Crossman, Powell, Principe, \& Ceci, 2002; Guadagno \& Powell, 2009; Kahneman, 1973; Powell \& Snow, 2007) and the interviewer refrains from pressing for answers (Chrobak \& Zaragoza, 2008, 2013).

An equally substantial portion of research into witness testimony optimisation concentrates on memory deterioration with age. The literature on memory is very robust, and shows that the ability to recall an event deteriorates more quickly with age than the ability to merely recognise a given event (Cansino, 2009; Chen \& Naveh-Benjamin, 2012; Lamb et al., 2008; Nilsson, 2003; Old \& Naveh-Benjamin, 2008; Tulving, 1985a, 1985b, 1995, 2002). While some conflicting research results suggest that the above conclusions may be erroneous and may have resulted from the ceiling effects caused by testing procedures that were too simplistic (Uttl, Henry, \& Baltimore, 2007), this was refuted with a study that specifically addressed these ceiling effects (Danckert\& Craik, 2013). Moreover, there is corroborating evidence from brain imaging that recall and recognition rely on different brain substrates (Glisky, Polster, \& Routhieaux, 1995; Vilberg \& Rugg, 2008), which underscores the importance of differentiating between recognition and recall in witness testimony (Lamb et al., 2008). Given that older adults' recall abilities deteriorate more quickly with age, that recognition does not deteriorate as quickly (Cansino, 2009; Nilsson, 2003; Old \& Naveh-Benjamin, 2008), interviewers of older witnesses might consider emphasising recognition over recall questions.

In conclusion, it is important to differentiate between recognition and recall in witness testimony. In this context, it is vital to acknowledge that recall and recognition memory systems develop differently over the human lifespan, and that the recall of older witnesses may not be as reliable as their recognition. Witness interviews could be designed accordingly. The deliberate planning of witness testimony commensurate with the differences in recall and recognition will aid in preventing inadvertent false testimony and subsequent retractions.

\section{Conclusion}

The central theme of this paper was the continuing influence of withdrawn witness testimony on the jury. The continuing impact of withdrawn testimony was discussed in relation to the wellresearched concept of the continued influence effect. Options to minimise this effect were explored, including offering a coherent alternative explanation instead of a simple withdrawal of the testimony. Furthermore, potential concomitant factors were examined to elucidate how they 
affect the severity of the continued influence. Ethnic differences between the jury and the accused were explored regarding their potential to cause juror prejudice and to increase the strength of the continued influence effect. Options to decrease prejudice were debated in the context of the intergroup contact hypothesis and research on indirect intergroup contact. Moreover, options were discussed for how to improve the quality of witness testimony to avoid retractions of testimony in the first place, including using open rather than closed questions, and clearly differentiating between recall and recognition.

The literature was summarised and improvement suggestions were offered based on relevant research. To prevent false testimony in the first place, interventions could be designed to increase the uptake of suitable techniques by interviewers. In order to minimise the temptation to fabricate, open questions could be used, avoiding pressing of the witness repeatedly for answers. If a withdrawal of testimony is necessitated, then a coherent alternative explanation should be given to fill the event model gap produced by the retracted false statement instead of a simple withdrawal. It was also suggested that more attention needs to be given to careful jury selection to minimise potential juror prejudice and, thereby, decrease the continued influence effect. A promising avenue for further research is the possibility that selecting more young, female, and well-educated individuals as jurors may diminish jury prejudice. Furthermore, it is important to differentiate between recognition and recall in witness testimony, to acknowledge that both memory systems develop differently over the human lifespan, and to plan witness interviews accordingly.

In summary, it is important to minimise the continued influence effect of withdrawn testimony in jury trials, as the implications for individual lives and justice in general are far reaching. A number of improvements have been suggested for how the proceedings surrounding eye witness accounts during jury trials could be improved to serve justice better. However, suggesting improvements of the legal system might imply that the current legal system contains injustices, which might cause cognitive dissonance in people: the more threatened their sense of a just world, the more likely they are to ignore the observed injustices (Adams, 1965). This situation makes improvements in the legal system difficult (Haney, 1980). 


\section{References}

i. $\quad$ Adams, J. S., 1065. Inequity in social exchange, s.l.: Advances in Experimental Social Psychology.

ii. $\quad$ Allport, G. W., 1954. The nature of prejudice, Oxford, England: Addison-Wesley.

iii. Barlow, F. K. et al., 2012. The contact caveat. Negative contact predicts increased prejudice more than positive contact predicts reduced prejudice, Volume 38, pp. 1629-1643.

iv. Bortner, M. A., 1982. Inside a juvenile court.The tarnished ideal of individualized justice, New York: New York University Press.

v. Brehm, J. W., 1966. A theory of psychological reactance, New York: Academic Press.

vi. Broadbent, D. E., 2013. Perception and communication, Oxford: Pergamon Press.

vii. Cansino, S., 2009. Episodic memory decay along the adult lifespan. A review of behavioral and neurophysiological evidence, Volume 71, pp. 64-69.

viii. Cantrall, A. M., 1959. The judge as a leader. The embodiment of the ideal of justice, Volume 45, pp. 339-342.

ix. $\quad$ Carvan, J., 2015. Studying law, NSW: Thomson Reuters (Professional) Australia Ltd.

x. Chen, T., Naveh \& Benjamin, M., 2012. Assessing the associative deficit of older adults in long term and short-term/working memory. Psychology and Aging, Volume 27, pp. 666-682.

xi. Chrobak, Q. M. \& Zaragoza, M. S., 2008. Inventing stories: Forcing witnesses to fabricate entire fictitious events leads to freely reported false memories. Psychonomic Bulletin \& Review, Volume 15, pp. 1190-1195.

xii. Chrobak, Q. M. \& Zaragoza, M. S., 2013. When forced fabrications become truth: Causal explanations and false memory development. Journal of Experimental Psychology, Volume 142, pp. 827-844.

xiii. $\quad$ Clear, T. R. \& Karp, D. R., 1999. The community justice ideal: Preventing crime and achieving justice, Boulder, Co: Westview Press.

xiv. $\quad$ Crossman, A. M., Powell, M. B., Principe, G. F. \& Ceci, S. J., 2002. Child testimony in custody cases. Journal of Forensic Psychology Practice, Volume 2, pp. 1-31.

xv. D. Capozza, Trifiletti, E., Vezzali, L. \& Favara, I., 2013. Can intergroup contact improve humanity attributions. International Journal of Psychology, Volume 48, pp. 527-541.

xvi. Danckert, S. \& Craik, F. I. .. M., 2013. Does aging affect recall more than recognition memory. Psychology and Aging, Volume 28, pp. 902-909.

xvii. Darvish, T., Hershkowitz, I., Lamb, M. \& Orbach, Y., 2008. The effect of the NICHD interview protocol on the elicitation of investigative leads in child sexual abuse investigations. Jacksonville, Florida, American Psychology-Law Society Conference.

xviii. $\quad$ E. Tulving, 1995. Organization of memory. In: M. S. Gazzaniga, ed. The cognitive neurosciences. Cambridge Ma: Mit Press.

xix. Ecker, U. H., Lewandowsky, S., Swire, B. \& Chang, D., 2011. Correcting false information in memory: Manipulating the strength of misinformation encoding and its retractions. Psychonomic Bulletin \& Review, Volume 18, pp. 570-578.

xx. $\quad$ Ecker, U. K. .. H., Lewandowsky, S., Fenton, O. \& Martin, K., 2014. Do people keep believing because they want to?. Preexisting attitudes and the continued influence of misinformation, Volume 42, pp. 292-304. 
xxi. Ecker, U. K. .., Lewandowsky, S. \& Apai, J., 2010. Terrorists brought down the plane No actually it was a technical fault: Processing corrections of emotive information. The Quarterly Journal of Experimental Psychology, Volume 64, pp. 283-310.

xxii. Farrelly, C., 2007. Justice in ideal theory. Political Studies, Volume 55, pp. 844-864.

xxiii. Fraser, H. \& Stevenson, B., 2014. The power and persistence of contextual priming: More risks in using police transcripts to aid jurors' perception of poor quality covert recordings. International Journal of Evidence \& Proof, Volume 18, pp. 205-229.

xxiv. Gaertner, S. L., Dovidio, J. \& Bachman, B., 1996. Revisiting the contact hypothesis: The induction of a common ingroup identity.. International Journal of Intercultural Relations, Volume 20, pp. 229-235.

xxv. Gaertner, S. L. \& Dovidio, J. F., 2012. Reducing intergroup bias.The common ingroup identity model, New York: Routledge.

xxvi. Greenhalgh, E. M. \& Watt, S. E., 2015. Preference for consistency and value dissimilarities in dehumanization and prejudice toward asylum seekers in australia. European journal of Social Psychology, Volume 45, pp. 110-119.

xxvii. Greitemeyer, T., 2014. Article retracted, but the message lives on, s.l.: Psychonomic Bulletin \& Review.

xxviii. Greitemeyer, T. \& Sagioglou, C., 2015. Does exonerating an accused researcher restore the researcher's credibility?, s.l.: Plos One.

xxix. Guadagno, B. L. \& Powell, M. B., 2009. A qualitative examination of police officers' questioning of children about repeated events. Police Practice and Research. An International Journal, Volume 10, pp. 61-73.

xxx. Haney, C., 1980. Psychology and legal change: On the limits of a factual jurisprudence. Law and Human Behavior, Volume 4, pp. 147-199.

xxxi. Hans, V. P., 2017. Jury systems around the world. [Online] Available [Accessed 15 April 2017].

http://scholarship.law.cornell.edu

xxxii. Hans, V. \& Vidmar, N., 1991. The American jury at twenty- five years. Law \& Social Inquiry, Volume 16, pp. 323-352.

xxxiii. Haslam, N. \& Holland, E., 2012. Attitudes towards asylum seekers. In: D. a. B. N. Bretherton, ed. The australian experience. US: Springer.

xxxiv. Hewstone, M., Rubin, M. \& Willis, H., 2002. Intergroup bias, s.l.: Annual Review of Psychology.

xxxv. Johnson, H. M. \& Seifert, C. M., 1994. Sources of the continued influence effect: When misinformation in memory affects later inferences. Journal of Experimental Psychology, Volume 20, pp. 1420-1436.

xxxvi. Kahneman, D., 1973. Attention and effort, Nj: Englewood Cliffs.

xxxvii. $\quad$ Kairys, D., Schulman, J., Harring, S. L. \& Beeler, J., 1975. The jury system: New methods for reducing prejudice, US: Springer.

xxxviii. $\quad$ Lamb, M., Hershkowitz, I., Orbach, Y. \& Esplin, P., 2008. Tell me what happened, Chichester,Uk and Hoboken, New Jersey: Wiley.

xxxix. Mazziotta, A., Mummendey, A. \& Wright, S. C., 2011. Vicarious intergroup contact effects applying social-cognitive theory to intergroup contact research. Group Processes \& Intergroup Relations, Volume 14, pp. 255-274. 
xl. McNulty, J., 2017. Nations embracing jury system as part of 'wave of judicial reform,' says uc santa cruz expert. [Online] Available at: http://news.ucsc.edu[Accessed 15 April 2017].

xli. Nilsson, L. G., 2003. Memory function in normal aging, s.l.: Acta Neurologica Scandinavica.

xlii. Oberdiek, J., 2014. The ideal of justice. Jurisprudence, Volume 5, pp. 363-368.

xliii. Oeberst, A. \& Blank, H., 2012. Undoing suggestive influence on memory: The reversibility of the eyewitness misinformation effect. Cognition, Volume 125, pp. 141-159.

xliv. Old, S. R., Naveh \& Benjamin, M., 2008. Differential effects of age on item and associative measures of memory. Psychology and Aging, Volume 23, pp. 104-118.

xlv. $\quad$ Pettigrew, T. F. \& Tropp, L. R., 2006. A meta-analytic test of intergroup contact theory. Journal of Personality and Social Psychology, Volume 90, p. 751.

xlvi. Powell, M. B. \& Snow, P. C., 2007. Guide to questioning children during the free-narrative phase of an investigative interview. Australian Psychologist, Volume 42, pp. 57-65.

xlvii. Roediger, H. \& Mcdermott, K., 2000. Distortions of memory. The Oxford Handbook of Memory, pp. 149-162.

xlviii. Schiappa, E., Gregg, P. B. \& Hewes, D. E., 2005. The parasocial contact hypothesis. Communication Monographs, Volume 72, pp. 92-115.

xlix. Schrag, J. \& Scotchmer, S., 1994. Crime and prejudice: The use of character evidence in criminal trials. Journal of Law, Economics, \& Organization, Volume 10, pp. 319-342.

1. Steffens, M. C. \& Mecklenbräuker, S., 2007. False memories: Phenomena, theories, and implications. Zeitschrift für Psychologie/Journal of Psychology, Volume 215, pp. 12-24.

li. Tulving, E., 1985. How many memory systems are there?. American Psychologist, Volume 40, pp. 385-398.

lii. Tulving, E., 1985. Memory and consciousness. Canadian Psychology/Psychologie Canadienne, Volume 26, pp. 1-12.

liii. Tulving, E., 2002. Episodic memory:From mind to brain. Annual Review of Psychology, Volume 53, pp. 1-25.

liv. Turner, R. N., Crisp, R. J. \& Lambert, E., 2007. Imagining intergroup contact can improve intergroup attitudes. Group Processes \& Intergroup Relations, Volume 10, pp. 427-441.

lv. Uttl, B., Henry, M. \& Baltimore, K., 2007. Are smaller age declines on old/new recognition vs.free recall tests artifacts of easy memory tests. Canadian Journal of Experimental Psychology, Volume 61, p. 374.

lvi. Vilberg, K. L. \& Rugg, M. D., 2008. Memory retrieval and the parietal cortex. A review of evidence from a dual-process perspective. Neuropsychologia, Volume 46, pp. 1787-1799.

lvii. Wortman, C., Brehm, J. W. \& Berkowitz, L., 1975. Responses to uncontrollable outcomes. Advances in Experimental Social Psychology, Volume 8, pp. 277-336.

lviii. Wright, B. R. .. et al., 1999. Reconsidering the relationshup between ses and delinquency. Criminology, Volume 37, pp. 175-194.

lix. Zaragoza, M. S. et al., 2001. Interviewing witnesses: Forced confabulation and confirmatory feedback increase false memories. Psychological Science, Volume 12, pp. 473-477.

lx. Zwaan, R. A. \& Radvansky, G., 1998. Situation models in language comprehension and memory. Psychological Bulletin, Volume 123, pp. 162-185. 